\title{
Percepción y lenguaje: Herder o la vanguardia de la hermenéutica
}

\section{Perception and language: Herder or the avant- garde of hermeneutics}

\author{
ADRIANA RODRÍGUEZ BARRAZA \\ Universidad Anáhuac y Veracruzana (México)
}

Recibido: 12-06-2007 Aprobado definitivamente: 29-10-2007

\section{RESUMEN}

El objetivo es analizar la génesis y la relación teórica Herder-Kant en la Metacrítica que insiste en la existencia concreta de los propios pensamientos, ideas y sistemas filosóficos cuyo verdadero a priori sería el lenguaje utilizado por los hombres que piensan; pero estos hombres no son universales abstractos, sino singulares concretos que dependen de una lengua, de una nación, en fin, de unas costumbres y formas de ser determinadas que los hace estar unidos íntimamente a su suelo-raíz. De esta manera, Herder abre el horizonte de la hermenéutica y del multiculturalismo.

\section{PALABRAS CLAVE \\ LENGUAJE, PENSAMIENTO, FILOSOFÍA CRÍTICA}

\begin{abstract}
The article intends to analyze the genesis of Herder-Kant theoretical relation in Methacritic, that insists on the concrete existence of thoughts, ideas and philosophical systems which a priori would be the language used by the thinking men. But these men are not universal abstracts, but concrete singulars, who depend on a nation, a language, habits and determined ways of being, that make them be strongly linked to their root-ground. In that way, Herder opens the horizon of hermeneutics and multiculturalism.
\end{abstract}

\section{KEYWORDS \\ LANGUAGE, THOUGHT, CRITICAL PHILOSOPHY}

\footnotetext{
(C) Contrastes. Revista Internacional de Filosofía, vol. XIII (2008), pp. 61-78. ISSN: 1136-4076 Licenciatura de Filosofía, Universidad de Málaga, Facultad de Filosofía y Letras Campus de Teatinos, E-29071 Málaga (España)
} 


\section{KANT DE KÖNISBERG, ENTRE LA ADMIRACIÓN Y EL RESENTIMIENTO}

KANT FUE UNO DE LOS PERSONAJES claves que marcaron la vida de Herder. En una primera etapa encontramos esa juvenil admiración del alumno por su maestro, 20 años mayor que él, y que lo lleva a escribir sobre sus cualidades y lo que esto produjo en su sensible alma. Herder asiste a las clases de Kant en 1762, a la impresionable edad de 18 años, lo que nos muestra, por ejemplo, esta carta:

De mis años juveniles recuerdo con gratitud y alegría el conocimiento y las clases de un filósofo que era para mi el auténtico maestro de humanidad. Entonces, en la plenitud de sus años, poseía la feliz agilidad de un adolescente, agilidad que creo le acompañará hasta su más avanzada edad. Su frente abierta, hecha para el pensamiento, era el asiento de la amenidad, y de su boca locuaz fluía el discurso más agradable y más denso de pensamientos. La broma, el ingenio, el buen humor, se hallan, a su disposición, en el momento oportuno, de forma que si alguien reía, el permanecía serio. Su exposición pública era como un trato conversacional. Hablaba sobre su autor, pensando por sí mismo, a menudo yendo más allá de él. Pero, durante los tres años en los que le oí a diario y acerca de todas las ciencias filosóficas, nunca advertí en él el menor grado de arrogancia. [...] Oí de el sus juicios sobre Leibniz, Newton, Wolff, Crusius, Baumgarten, Helvetius, Hume, Rosseau, algunos de los cuales eran escritores recientes; observé el uso que hacía de ellos y no encontré en él sino un noble celo por la verdad, el más bello entusiasmo por los descubrimientos importantes para el bien de la humanidad, la más desinteresada emulación de todo lo grande y bueno. No sabía de cábalas, y el espíritu de partido o de secta le era completamente extraño; el ganar discípulos o el dar incluso su nombre a algún grupo de seguidores no era la corona a la que aspiraba. Su filosofía despertaba el pensamiento propio, y no puedo imaginarme nada más exquisito y eficaz, a este respecto, que su exposición: sus pensamientos parecían manar de él al instante; había de seguir pensando con el; el dictar, adoctrinar y dogmatizar, le eran desconocidos. La historia natural, la teoría de la naturaleza, la historia humana y la de los pueblos, las matemáticas y la experiencia, eran las fuentes preferidas de su saber humano, de las que extraía, a partir de las que vivificaba todo. A ellas remitía. Su alma vivía en la sociedad, y todavía recuerdo las amables palabras que me dijo sobre ello al despedirme. Ese hombre, amigo mío, se llamaba Immanuel Kant; tal es su imagen delante de mi. ${ }^{1}$

A Herder impactan varias cuestiones de su profesor que veremos plasmadas en sus obras como, por ejemplo, ser un maestro en humanidad y que su alumno procuró «introducir en la escuela el concepto de la humanidad y hacer de él

1 Citado por Ribas en Obra Selecta. Prólogo, Traducción y notas de Pedro Ribas. Madrid: Alfaguara, 1982. pp. XXXVII-XXXVIII. Tomado de Brefe zur Beförderung der Humanität, Berlín y Weimar, Aufbau Verlag, 1971 (2vols.), Vol 2 pp. 350-351. 
una estrella conductora en la formación de la juventud». ${ }^{2}$ Desde la temprana época de Riga se puede ver este propósito: el despertar el pensamiento propio y evitar convertirse en «el aprendiz de papagayo e ignorante que no hace más que repetir», ${ }^{3}$ idea que Herder modelará en sus planes educativos. Respecto a la temática, que después desarrollará en sus escritos, se inclina por la parte de la historia natural, ${ }^{4}$ lo relacionado con la antropología, los pueblos, ${ }^{5}$ las matemáticas; pero, sobre todo, el conocimiento siempre unido a la experiencia. ${ }^{6}$ Esta influencia se ve claramente en sus ideas pedagógicas del Diario.

Tomemos en cuenta que en Kant distinguimos algunos periodos. Primero (1746-1760), donde prevalece el interés por las ciencias naturales y que filosóficamente, se inclina por el racionalismo. Segundo (1760-1769), donde aventaja la vocación filosófica y apunta hacia el empirismo. Tercero (1769-1781), en donde comienza la idea criticista y que aunque se encuentra en estado embrionario. En el cuarto (1781-1804), se da la sistematización de ese criticismo, cuyo método trascendental hace que la Crítica de la razón pura (1781) se convierta en una de las grandes obras.

Este admirado Kant es el mismo que el 7 de mayo de 1768, hacia el final del periodo precrítico, le escribe a Herder:

Con profunda indiferencia respecto a mis propias opiniones y a las de los otros, subvierto a menudo la entera estructura del pensamiento y lo considero desde varios puntos de vista a fin de dar quizá finalmente con la posición que me permita diseñar el sistema correcto [...]. Desde que nos separamos, he procurado dejar espacio en muchas partes para otras perspectivas. Mientras mi atención ha estado dirigida a reconocer el verdadero fin y lo límites de las capacidades e inclinaciones humanas, creo haber alcanzado finalmente el éxito en gran medida en lo que a la moral se refiere. Ahora trabajo sobre una metafísica de las costumbres. Y me parece que

$2 C f$. Rosario Fuentes, Herder y su ideal de humanidad, Madrid: Ediciones de la lectura, 1930. p. 101.

3 Cf. Johann Gottfried Herder: Werke, I, Journal meiner Reise im Jahr 1769. Editado por M Bollach, M Deutschen Klassier Verlag 1997. p.39. En adelante JR.

$4 C f$. Herder: Werke, I, $J R$ p. 43. « ¿He aquí cómo el principio de la geografía se convierte, de modo natural en geografía física! Aquí se juntan ciencia natural, historia natural, algo de matemáticas y muchos datos, muchos fenómenos, muchos relatos».

$5 \quad I b i d$, p. 43. «Aquí se extiende la anterior historia natural: descubro que cada país tiene sus propios hombres y criaturas; en todas partes trabo conocimiento con ellos; aprendo a situar a cada uno en su sitio y a comprender el conjunto entero del que todo forma parte, el cuerpo entero de la Tierra».

6 Ibid, p. 118. «[...]ni una palabra sin concepto ni un concepto anticipado; nada más que aquello que un alma humana sea capaz de entender por sí misma según su edad; en los primeros años ello no quiere decir otra cosa que conceptos pasados por los sentidos». 
estoy en posición de poder indicar los evidentes y fructíferos principios de ésta, como también el método que los esfuerzos viables deben seguir en este tipo de conocimiento, incluso aunque tales esfuerzos se muestren a menudo inútiles. ${ }^{7}$

Con estos dos ejemplos epistolares, a pesar de la diferencia de edades, podemos hacernos una idea de que ambos mantenían una amistad y confianza mutua, lo que lleva a Kant a expresarle sus más profundas dudas, pensamientos y proyectos intelectuales.

\section{LAS OPINIONES DEL METAPHYSICUS}

Pero la relación no siempre fue así; de ello nos podemos dar cuenta expresamente en la Metacrítica. Ésta es una obra que se encuentra escrita en un tono cáustico, avinagrado; la transformación forma parte de una segunda etapa en las relaciones Herder-Kant, y este cambio tan radical llega a transformarse, con el tiempo, en franca enemistad en la que ambos autores, con los recursos intelectuales tan diferentes con los que cuentan, refutan las teorías del contrario. Expondremos a continuación qué es lo que ocurrió.

En 1784 se fundó la revista Neue allgemeine Literaturzeitung de Jena y se le pidió a Kant colaborar enviando una recensión de las Ideas sobre la filosofía de la historia de la humanidad ${ }^{8}$ (1784) de su antiguo alumno. Acepta empleando la copia que poseía de Hamann. La reseña se publicó el 6 de enero de 1785 y, según los usos de la época, tenía un carácter anónimo ${ }^{9}$ (recordemos que la publicación de las Silvas escritas por Herder en 1769 también fue anónima). Al leer la recensión de 29 páginas nos podemos dar cuenta de la opinión poco favorable que tenía en esos momentos Kant de la obra de Herder. ${ }^{10}$

El contenido de esta recensión, ${ }^{11}$ que se refiere a la primera parte de Ideas, pretende indicar lo más importante, incluso empleando las propias nociones de

7 Citado por Manfred Kuehn: Kant. Una biografía. Tr. Carmen García-Trevijano. Madrid: Acento 2003, p. 263.

$8 \quad C f$. Johann Gottfried Herder en Obra Selecta. Prólogo, Traducción y notas de Pedro Ribas. Madrid: Alfaguara, 1982. p. XLVI. Ideas sobre la filosofía de la historia de la humanidad. La primera parte es de 1784, (y corresponde a la recensión) la segunda la escribe en ese mismo año, la tercera data de 1787 y la cuarta de 1791. El editor es el mismo de la Crítica de la razón pura (1781).

9 Herder supo de la autoría de Kant al leer la recensión y posteriormente lo confirmó al recibir una carta de Hamann quien le pedía discreción por el dato.

10 Cf. Kuehn: op. cit. pp. 410- 412 y 423.

$11 C f$. Kant: En defensa de la Ilustración. «Recensión de las Ideas para la filosofía de la historia de la humanidad de Johann Gottfried Herder» Recensión zu Johann Gottfried Herders «Ideen zur Geschichte der Menschheit» (1785), Madrid: Alba Editorial, 1994, pp. 115-144. 
Herder y, posteriormente, incluirle ciertas notas. Dada la complejidad de nuestro autor y la sistematicidad de Kant, pensamos que supuso un enorme esfuerzo hacerlo. Para los fines de nuestro estudio no es el caso analizar las Ideas para la filosofía de la historia de la humanidad (1784), sino su influencia y directa repercusión en la Metacrítica. Lo señalaremos en dos partes.

1. Por un lado, las críticas negativas que se dan desde el inicio. Respecto del título Filosofía de la historia de la humanidad, para Kant parecería algo lógico y con conceptos claros, precisos; pero no es así, se encuentra con una obra llena de sensaciones, sentimientos, estímulos, impresiones, donde la intensa imaginación y fantasía de su autor oscurecía continuamente lo sustancial. Cuando Herder afirma que el hombre puede llegar a un futuro de vida más elevado y así al infinito, Kant no puede entender en todo su sentido cómo llega a esa conclusión con tales premisas en la argumentación y lo menciona del siguiente modo: «El recensor debe confesar que tampoco comprende esta conclusión que se sigue de la analogía con la naturaleza, aún cuando concediera aquella continua gradación de sus criaturas, además de su propia regla; a saber: el acercamiento del hombre». ${ }^{12}$ De igual modo, señala que Herder quiere explicar lo que no se comprende a partir de lo que se entiende aún menos, ${ }^{13}$ y lo invita a que deje de cultivar exuberantes retoños y más bien pode y delimite las fundamentales cuestiones; a que no use insinuaciones sino conceptos, a que no se deje llevar por el ánimo, la imaginación o los sentimientos, sino por la razón; que procure evitar el empleo de sinónimos como explicaciones y alegorías por verdades, puesto que no es lo más correcto, así mismo le advierte que al emplear atrevidas metáforas poéticas y usar continuas alusiones mitológicas, sólo consigue empañar y desdibujar los pensamientos. Finalmente, comenta que posee ante todo un torrente de elocuencia con lo que trata de persuadir, no de razonar.

Kant echa de menos una cabeza histórico-crítica. Le parece que reúne datos dispersos en un solo punto de vista y que emplea un peculiar camino de pensamiento. Encuentra a Herder antagónico con lo que en la época se denomina «filosofía» en estricto sentido.

2. Las críticas positivas sí existen y se refieren básicamente a que es una obra rica en singulares ideas, libertad de pensamiento, que posee una cabeza fructífera, así como juicios agudos y también una poética elocuencia.

Lo que Kant pretende con las mejores intenciones es prácticamente imposible: pedir peras al olmo, puesto que, de ser así, Herder dejaría de ser Herder, 
tendría que volver a nacer y, usando una de sus metáforas, sería como pedir que «un león sea parido por una oveja».

Con estas declaraciones, el carácter susceptible de Herder se ve afectado a tal grado que su respuesta no se hace esperar, se encontró traicionado por su propio maestro, y en una carta a Hamann le escribe dolorosamente lo siguiente:

El año pasado anunciaron con gran pompa en Jena la aparición de una nueva revista literaria, y Kant fue mencionado como uno de sus primeros colaboradores. Y efectivamente y en los números 4 y 5 me encontré con una recensión de mis Ideas, que es tan maliciosa, distorsionante, metafísica y tan completamente alejada desde el principio al fin del espíritu del libro, que me dejó estupefacto. Nunca habría esperado yo que Kant, mi maestro, a quien nunca he insultado, fuera capaz de tan mezquino acto. Me pregunté una y mil veces quien podría escribir en Alemania de manera tan completamente ajena al horizonte de nuestro país y del libro, hasta que empezaron a correr los rumores y finalmente se dijo abiertamente: era el gran metaphysicus Kant de Könisberg, Prusia. Al mismo tiempo leía su «Idea para una historia universal de la humanidad», [que se suponía escrita] en clave cosmopolita y a medida que leía este ensayo fui aprendiendo también algo sobre el carácter del recensor, pero nada sobre el carácter del hombre. Porque cuán malicioso e infantil resulta contemplar desde su Prefacio el plan de un libro incompleto y apenas empezado, tomarlo y utilizarlo a la manera de un libro acabado, mientras su autor se muestra como si no hubiera ningún otro libro de este tipo en el mundo... Por fortuna, ahora sólo que puedo esperar del Magistro VII. Artium; feliz yo por no necesitar ese infantil plan creado por él al servicio de la especie y de la más perfecta máquina gubernamental (Staatsmaaschine) del final de los tiempo. Lo que yo le pido, mi querido amigo, es que no continúe usted enseñándole en el futuro mis escritos prima manum y no vuelva a transmitirle mis recuerdos. Dejo el tono metafísico-crítico del juicio al Sr. Apolo, que él desea escalar, porque para mí está lleno de niebla y de confusas vocingleras nubes. No le diga usted que yo conozco la recensión y al recensor... Me sentiré muy contento si alarmo a su ídolo de la razón o lo reduzco a cenizas. Sus profesorales instrucciones me resultan decididamente indecentes. Tengo cuarenta años y no me siento ya en el banco de la escuela metafísica. La fístula causada por mi negativa al seguir al Herr profesor en su trillada senda de fantasías conceptuales (Wortgaukelein)... El orgullo [del metafísico] y su insoportable autoimportancia, que queda también demostrada por las cartas de Kant a Lambert, es sencillamente algo cómico. ${ }^{14}$

Con este escrito comprobamos el efecto tan perjudicial y devastador que produjeron en Herder los comentarios negativos de un hombre al que el tenía

14 Citado por Kuehn: op .cit. p. 415. 
en alta estima y era de una talla intelectual mayor. El enfado fue tan grande que Herder llego a acusar a Kant de haber plagiado en sus Ideas para la historia universal en clave cosmopolita (1784) los conceptos básicos de Ideas para una filosofía de la historia de la humanidad (1784). Podemos decir que sí se encuentra una similitud y que, probablemente, Kant tomara ciertas ideas como contraste a sus propias argumentaciones; pero, en su conjunto, es fundamentalmente distinto.

Posteriormente, Kant criticó la segunda parte de las Ideas (1784) en el Allgemeine Literaturzeitung del 15 de noviembre de 1785. De esta crítica destacamos algún sentido positivo cuando se refiere a los libros 6 y 7; menciona que están «seleccionados con acierto», «dispuestos con maestría», «acompañados en todo momento por opiniones propias e ingeniosas» $\mathrm{y}$ «llenos de bellos pasajes». ${ }^{15}$

Como contrapartida, y dado que Kant procuraría ser objetivo, no podía faltar el juicio negativo donde surge la pregunta de sí el espíritu poético tan socorrido por Herder no hacía más que encubrir la verdadera filosofía del autor. Con ese espíritu lo que se lograba era oscurecer, confundir y perder el todo por la parte, y además le faltaba el más mínimo orden necesario en la pretendida evidencia que supuestamente quería mostrar.

Kant continúa con las críticas a los escritos de Herder y como éste escribió en abundancia, las críticas también lo fueron; le molestaba el rechazo que Herder mantenía al concepto de raza, especialmente «cuando esta división estaba basada en el color hereditario». ${ }^{16}$ Kant afirmaba que hubo una única especie de hombre que tuvo dentro de sí las cuatro posibilidades de raza. Herder, por su lado, consideraba que por la intervención del clima el hombre se ha ido configurando «por la innata fuerza vital genética en diferentes apariencias». ${ }^{17}$

Nuestro autor recibió igual de mal esta crítica, como era de suponerse, y Kant, por su parte, en noviembre de 1785 publica en Berlinische Monattsschrift un ensayo sobre La definición del concepto de raza humana. Ahí expone, entre otras cosas, que la raza estaba basada en rasgos heredados y los hijos de relaciones mixtas heredaban características de las dos razas; por lo que no existen especies diferentes de seres humanos.

En los siguientes dos volúmenes de Ideas, Kant ya no continuó con estas críticas; en cambio redacta Probable inicio de la historia humana, donde expresa que las cosas evolucionan de lo peor a lo mejor. Herder pensaba que lo que Kant consideraba como progreso o como una época que ha ido a mejor, realmente empobrecía a la humanidad y se encontraban en una situación grave. Existen varios ejemplos de características negativas que Herder advierte y que

15 Ibid, p. 417.

16 Ibid, p. 419.

17 Cf. Baur, Ernst: Juan Godofredo Herder. Vida y Obra. Madrid: Tecnos 1968. p. 132. 
emplea para hacer un dibujo agridulce de su tiempo. En Otra filosofía escribe: «su vida se alimenta de librepensamiento. Caro, agotado, fastidioso, inútil librepensamiento, sustituto de lo único que quizá les haría falta: ¡corazón, calor, sangre, humanidad, vida!»; ${ }^{18}$ y más adelante: «Libertad, vida social e igualdad, tal como brotan ahora por todas partes: han causado daños en mil abusos y lo seguirán causando»; $;^{19}$ en fin, al referirse a la Ilustración apuntilla:

[...] junto a la Ilustración ha tenido que extenderse, por una ley natural de la imperfección de los actos humanos, una voluptuosa fatiga del corazón; junto a la economía su signo y su consecuencia, la pobreza; junto a la filosofía, la ciega y miope incredulidad; junto a la libertad de pensamiento, la esclavitud de los actos, el despotismo sobre las almas bajo cadenas de flores [...]. ${ }^{20}$

Años más tarde, en 1787, Herder escribió Dios, algunas conversaciones, en donde trata de rehabilitar a Spinoza (1632-1677), y no deja pasar la oportunidad para dirigir algunas indirectas a Kant.

Como podemos observar se trata de una disputa que se prolonga en el tiempo y Herder, da un gran cambio acerca de la idea que tenía de su profesor. El alumno toma la contienda más bien como un asunto personal y Kant, por lo que a él respecta, como un asunto de deber. Estas polémicas acabaron en hostilidad abierta debido a la personalidad susceptible e insegura de Herder. ${ }^{21}$

Sin embargo, la tortuosa relación Herder-Kant va más allá de las meras críticas entre uno y otro, e influye de manera decisiva en el rumbo que toma por esos años la obra de Kant, es decir, que nuestro menos popular Herder, a pesar de su «peculiar» camino de pensamiento, juega un papel decisivo, nada más y nada menos, que en la tercera crítica, obra ésta de un filósofo de primer orden como lo era Kant. Zammito no tiene dudas de que Kant escribe la Crítica del juicio, (1790) ${ }^{22}$ motivado en gran parte por Herder y, es más, llega a afirmar que «esta crítica fue casi un continuado ataque a Herder»; en la mayor parte de la crítica del juicio teleológico se debe ver a Herder como un «innominado antagonista», ${ }^{23}$ y esta oposición sería el trasfondo contextual más importante de la obra. Kant debía refutar el exacerbado particularismo, así como el dogmatismo

18 Cf. Herder: Werke, II, $P H G$ p. 64.

19 Ibid, p. 98.

20 Ibid, pp. 103-104.

21 Cf. Kuehn: op.cit. p. 447.

22 Recordemos brevemente que La Crítica del juicio se encuentra dividida en: 1. La crítica del juicio estético que trata de la validez de los juicios estéticos y 2. Crítica del juicio teleológico donde Kant analiza el panteísmo y el teísmo -entre otras cosas-como soluciones al problema de la teleología y su tesis que las dos posturas son falsas.

23 Citado por Kuehn: op.cit. pp. 479-80. 
de Herder, el hilozoismo ${ }^{24}$ y la captación artística de la ciencia. No obstante esto no reduce para nada a mera polémica la obra. ${ }^{25}$

Para Kant, Herder «deseaba ser dictador y buscaba tener apóstoles». ${ }^{26}$ Esta negativa opinión sólo es comparable por la que existía por Fichte. Recordemos que Herder fue miembro de la masonería junto con Goethe, Lessing y otros intelectuales, concretamente dentro de un grupo fundado por el catedrático alemán Adam Weishaupt en 1776 en Baviera. Es verdad que antes de su desencanto sintió simpatía por la masonería y podemos pensar que Kant se encontraba muy lejos de cualquier grupo o secta de estas características. No siempre estuvo Herder de acuerdo con los procedimientos de la organización; de hecho escribió amargamente el 9 de enero de 1786, dos años después de la primera y segunda parte de Ideas y un año antes de la tercera, al Hermano filólogo Heyne: «sostengo un odio mortal a las sociedades secretas y, como resultado de mi experiencia, tanto dentro de sus círculos más íntimos y fuera de ellas, las mando a todas el demonio. Por las constantes conspiraciones para dominar y el espíritu de intriga que se arrastra bajo la cubierta».

Con las críticas de Herder, Kant se sentía desasosegado más que nada por la repercusión en la gente joven que podría rechazar su sistema y seguir un camino erróneo. ${ }^{27}$ Esta es la cuestión de fondo por la que Kant dedica parte de su tiempo en rebatir a Herder, la peligrosa, nociva y persuasiva influencia del «error». Nuestro autor, por su parte, seguía los escritos y proyectos de Kant a través de las cartas con Hamann y de las discusiones del momento.

En las Cartas para el fomento de la humanidad (1793-1797) Herder hace diez recopilaciones encontramos una censura más velada del empleo que se hacía del criticismo kantiano. Y a diferencia de la Metacrítica no se ensaña con la obra de Kant. En su siguiente escrito, Kalligone (1800), tres años antes de su muerte, la embestida se refiere esta vez a la Crítica del juicio (1790), en donde Kant, descubre puntos vulnerables, como por ejemplo «la falta de atención y valoración al lenguaje». ${ }^{28}$ Comprobamos así -y esta es nuestra tesis decisiva- que el lenguaje fue un tema vertebral hasta el final de sus días que lo diferencia de Kant.

Herder, junto con otros alumnos iniciales de Kant, no atinó a valorar la perspectiva filosófica del Kant maduro. ${ }^{29}$ Es cierto, pero hoy se puede decir que nos abrió otro mundo.

24 El hilozoismo concibe a la materia activa, viviente, dotada de espontaneidad.

25 Cf. Kuehn: op.cit. p. 480.

26 Citado por Kuehn: op.cit. p. 481.

27 Cf. Kuehn: op.cit. p. 457.

28 Cf. Ribas: op.cit. Introducción p. XL.

29 Cf. Kuehn: op.cit. p. 240. 


\section{MeTACRÍTICA}

Cuatro años antes de su muerte Herder publica la Metacrítica. ${ }^{30}$ Para estos momentos su fama había declinado ya, era un autor aislado a la sombra de Goethe y Schiller que resplandecían en el escenario. Esta es la penúltima obra de Herder, un autor ya maduro, que la redacta en Weimar donde vive desde 1776 hasta su muerte en 1803. En los siglos XVIII y XIX la corte de Weimar era uno de los centros intelectuales y literarios de Alemania más importantes donde confluían un sin número de intelectuales, artistas, etc. Entre los más importantes encontramos a Goethe, convocado expresamente en 1775 por el heredero del Ducado de Sajonia-Weimar para vivir ahí y donde permanece hasta su muerte (1832), con excepción de dos años que estuvo en Italia (1786-1788). Gracias a su buena posición y a un tiempo de buenas relaciones con Herder, ayuda a éste en varias ocasiones a encontrar y mantener un trabajo dados los problemas que ocasionaba por su peculiar modo de ser.

Nos remitiremos a analizar los fragmentos de la Obra Selecta. Herder defiende su postura frente a las obras de Kant de igual manera que el protestantismo se había definido frente al papismo dogmático, por lo que en esta sutil contextualización histórica Kant jugaría el papel de Roma y Herder el de Lutero. Sólo que aquí la clave de la libertad de conciencia y de poder leer las escrituras personalmente muestra una crítica general a la filosofía de Kant por no tener en cuenta el significativo y vertebral valor del lenguaje, ni tampoco el deseo de afirmarlo en su contexto nacional. Por esta razón, la primera serie de aclaraciones de esta obra que analizamos comienza criticando el refinamiento excesivo de la lengua de una nación porque «mutila el órgano más noble de multitud de jóvenes, haciendo extraviar su entendimiento mismo, cuyo ámbito nunca puede cerrarse a las especulaciones». ${ }^{31}$

Metacrítica quiere decir «crítica de la crítica» y parte de la imposibilidad que tenemos de juzgar desde la razón del hombre una razón superior. No hay más razón que la humana y aunque podamos aislarla mental y verbalmente, nunca, afirma Herder, subsiste por sí misma separada de otras facultades. Pero la crítica más acertada, es la que el propio Herder coloca en tercer lugar: «el alma humana piensa con palabras. Mediante el lenguaje no sólo se exterioriza, sino que se caracteriza a sí misma y sus pensamientos». Uno de sus fundamentos filosóficos lo recoge Herder de la teoría que Leibniz sostiene sobre el lenguaje

30 Cf. Johann Gottfried Herder: Eine Metakritik zur Kritik der reinen Vernunft. Werke Vol 8 Editado por M Bollach, M Deutschen Klassier Verlag 1997. pp. 303-640. Johann Gottfried Herder: Una metacrítica de la «Crítica de la razón pura» (Eine Metakritik zur Kritik der reinen Vernunft). En adelante $M V$.

31 Ibid, p. 305. 
como espejo del entendimiento humano. En donde la metáfora del «espejo» significa que el lenguaje es «una fuente de sus conceptos, un instrumento de su razón, no sólo habitual sino imprescindible». Herder avanza más lejos al poner en claro que única y exclusivamente podemos aprender a pensar a través del lenguaje. El siguiente pasaje es contundente:

Gran parte pues de los malentendidos, contradicciones y absurdos atribuidos a la razón no se deberán seguramente a ella misma, sino al defectuoso instrumento del lenguaje o a su incorrecto uso como indica la misma palabra «contradicciones». 32

Nadie debería pensar que se rebaja la noble crítica de la razón pura, advierte Herder, ni que la especulación más fina se convierta en gramática lo que abrirá el camino filosófico a Nietzsche. Aquí se acusa que Kant no haya tenido en

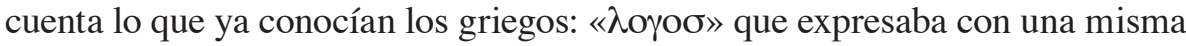
palabra la razón y el lenguaje.

Nuestra lectura de la Metacrítica se centrará, por consiguiente, en la cuestión del lenguaje. Herder duda que la filosofía pueda establecer una ciencia que determine los principios y la extensión de los conocimientos a priori. Consecuente con su forma de pensar advertirá lo que sigue:

Ahora bien, dado que un mismo entendimiento humano constituye sus conceptos, es decir, los enlaza, separa e indica de modo diferente en distintas lenguas; [...] se complica esa fácil ciencia que determina la posibilidad, los principios y la amplitud de todos los conocimientos a priori. ${ }^{33}$

Los juicios sintéticos a priori constituyen un error en el uso del lenguaje. Herder llama a estas patologías de la razón «metátesis» que es el metaplasmo ${ }^{34}$ consistente en el cambio de lugar los sonidos dentro de la palabra, atraídos o repelidos unos por otros. Estos juicios se habrían introducido sintéticamente en el lenguaje y, como son juicios carentes de fundamento, hay que retirarlos. ${ }^{35}$

$32 C f$. Herder: Werke, $8, M V$.

33 Cf. Herder: op.cit. p. 326.

34 Metaplasmo se refiere a las varias alteraciones de los vocablos en la estructura por diversas causas. El metaplasmo tenía lugar en la lengua poética; si ocurría en la lengua corriente, se denominaba barbarismo. Encontramos también una segunda acepción, que se denomina metaplasmo al cambio de género, por ejemplo, en centinela, o puente, que son femeninos en la lengua antigua y masculinos hoy; concretamente, se suele denominar también con la palabra metaplasmo al distinto género de una palabra en singular y en plural (latín locus, masculino; neutro). Cf. Lázaro Carreter, F.: Diccionario de términos filológicos, Madrid S. 276.

35 Cf. Herder: op.cit. p. 342. 
Siguiendo esta línea argumentativa se pregunta «jes, por tanto, posible sanar, corregir o llevar adelante la metafísica por medio de una estética trascendental, de una analítica trascendental, de una dialéctica trascendental?» Contestando que esto sería lo mismo que curar el mal con un mal mayor. La terminología usada por Herder nos lleva, utilizando el trabajo de R. Fourny La sana razón humana y su génesis natural. Critica de Herder a la filosofía trascendental, a hablar de una patología de la razón que habría que curar. El diagnóstico es el siguiente: «que la razón haya extraviado y perdido en ámbitos vacíos por trascenderse así misma». ${ }^{36}$ La filosofía crítica, la filosofía trascendental, sólo sería a juicio de Herder «un no-concepto», «una síntesis que va antes y es independiente de todo lo dado», en fin, «puros absurdos [...] de una razón previa a la experiencia de la razón»; por lo que corremos el peligro de «sofisticar enteramente, desde el comienzo, el verdadero uso de la razón». La dialéctica trascendental reafirmaría hasta el colmo todos estos males al convertirse en el puro arte de la polémica y de la disputa dialéctica. No habría camino más favorable ni más medicina que el camino opuesto:

El único camino favorable es precisamente el opuesto. En efecto, en lugar de trascender, vuelva la razón al origen de su obsesión, esto es, así misma, con las preguntas: «¿Cómo llegaste a ti y a tus conceptos? ¿Cómo los has expresado y empleado, encadenado y enlazado? ¿A qué se debe el que les atribuyas certeza universal, necesaria?». Si la razón prescinde de estas preguntas y se aísla de toda experiencia convendría que se aislara igualmente del lenguaje. En efecto, si lo posee es sólo gracias a la experiencia. Si cayera, en fin, tan de lleno en el reino de la ilusión, que atribuyera universalidad y necesidad a sus juicios antes de toda experiencia por ser tales juicios «a priori» (conforme a un erróneo empleo de esta expresión), es decir, por ser anteriores a toda experiencia e independientes de ella, entonces, existiría antes que la razón, la cual debe ser posibilitada, justamente con la experiencia, gracias a ella, inventándola sintéticamente «a priori» difícilmente puede hacerse un uso peor del lenguaje. A base de disfraces verbales se construye una suprarazón que secciona toda filosofía y únicamente permite ficciones, ex nullis ad nulla, o un a priori que se crea así mismo antes de existir, separado de sí y sin ninguna experiencia. ${ }^{37}$

La Metacrítica insiste en la existencia concreta de los propios pensamientos, ideas y sistemas filosóficos cuyo verdadero a priori sería el lenguaje utilizado por los hombres que piensan; pero estos hombres no son universales abstractos, sino singulares concretos que dependen de una existencia, de una lengua, de

36 Cf. Herder: op.cit. p. 342.

37 Ibid, p. 343. 
una nación, en fin, de unas costumbres y formas de ser determinadas que los hace estar unidos íntimamente a su suelo-raíz. De esta manera, Herder, abre el horizonte de la hermenéutica y del multiculturalismo, ${ }^{38}$ por lo que entendemos que, y a pesar del continuo zigzagueo de su obra, tenemos ante nosotros indudables hilos conductores de un pensamiento renovador, vivificador de una razón completamente disecada por el vacío abstracto de lo trascendental. El camino opuesto a seguir, que se abre al romanticismo y nacionalismo cultural, es tomar seriamente el punto del que parte la razón que de ninguna forma podemos aislarla del lenguaje porque forma parte integrante de nuestra propia experiencia.

El título Crítica de la razón pura tiene un radio de acción trascendental universal, que va más allá de lo particular concreto. Esto difiere totalmente de la caracterización monádica del pensamiento herderiano cuado nos señala las limitaciones a las que estaban sometidas cada forma de ser o de existencia. Por esto, si son el entendimiento y la razón las facultades que constituyen el distintivo de nuestra especie, el grandilocuente título de Crítica de la razón pura debería cambiarse por uno más realista y auténtico: «fisiología de las facultades cognoscitivas del hombre». ${ }^{39}$ La Crítica de la razón pura sería un disfraz verbal que trasciende tanto el espacio como el tiempo de la especie que lo está pensando, como si ésta especie tuviera la facultad supra perfectiva de pensar y expresar lo pensado desde la nada, o desde el más allá inventado por la propia especie.

Al contrario, para Herder todo nuestro ser, actuar y padecer, todo nuestro lenguaje estaría lleno de expresiones relativas al espacio; pero no como una condición trascendental, sino lingüística. Es interesante destacar los ejemplos del propio Herder. Las palabras «delante», «detrás», «a», «en», «junto a», «encima», «debajo» tienen que ver con el discurso entero como con el mundo de los conceptos contenido en tal discurso. Llamando la atención de los pequeños prefijos alemanes como «er-, ent-, gen-, ab-, zu-», que tanto dan a entender y que originariamente eran localizaciones o designaciones del lugar en el espacio. Nuestra percepción del espacio queda atada sin remedio a la lengua materna desde donde estas denominaciones «ordenan y examinan, por así decirlo, las percepciones del universo». Percepción y lenguaje es un territorio fenomenológico descubierto por Herder como si de un pionero se tratara. ${ }^{40}$

Y lo mismo ocurre con respecto al «tiempo»: «se adueñó de todo el conjunto linguiístico» de tal forma que lo rige todo y ordena también «la secuencia de los pensamientos humanos». Como todo actuar y padecer sucede en el tiempo «se

38 Esta filosofía de la cultura que contempla la pluralidad de lenguas y pueblos implica no un interculturalismo sino, más bien, un multiculturalismo dado que su fuente es monadológica.

39 Ibid, p. 343.

40 Heidegger sabrá sacar de aquí buena parte de su ontología. 
añadió el tiempo a todos los verbos activos y pasivos (Verba)». Al principio, escribe Herder, las diferencias eran escasas, observándose de forma tosca las del pasado y futuro. Poco a poco se fueron introduciendo «distinciones más finas» como ocurrió en la lengua griega y en ambas determinaciones temporales. Se añadieron a los verbos determinaciones «locales y temporales» a los verbos a través de partículas; así mismo, se mezclaron adverbios y preposiciones en el discurso y, finalmente, «las conjunciones encauzaron y guiaron toda su corriente conforme al tiempo». En nota a pie de página del propio Herder se afirma que las palabras que en alemán señalan la semana, el día y la hora «significan genéticamente los conceptos aquí indicado»; en otras lenguas se muestra lo mismo de manera distinta, pero siempre siguiendo «esa misma ley de un entendimiento que forma conceptos». La metodología de la Metacrítica, como un camino distinto al de la razón pura y su trascendentalidad, queda definida con esta breve nota:

Partiendo de los verbos y nombres y bajando hasta las partículas más pequeñas, se puede demostrar que todos han sido formados desde objetos reales y sensibles, a saber desde los más comunes y frecuentes. No se ha inventado ningún lenguaje previo a la experiencia, a priori y prescindiendo de ellas. ${ }^{41}$

Respecto al ser resulta que es el concepto básico de la razón y de su copia el lenguaje humano. No podríamos pensar ninguna percepción, como ningún concepto, ya sea en lo concerniente a la cosa o bien a su condición al tiempo o al lugar, ni al actuar o al padecer, sin que tengamos como fundamento un ser que mostramos o presuponemos. «El ser enlaza todo juicio del entendimiento; sin él no puede pensarse ninguna regla de la razón [...]». La influencia de Leibniz vuelve a aparecer, cuando Herder asevera que el ser se manifiesta a través de la «fuerza» porque, de lo contrario, no sería nada. La fuerza de sí mismo, venga de donde sea, continúa Herder, está ahí y perdura. Razón de que Existencia (Da sein) signifique estar en su lugar, confirmarlo. Mientras que Esencia (Wesen) quiere decir permanecer en su lugar, durar. Finalmente, Verdadero (Wahr) es lo que perdura y responde a las esperanzas depositadas en ello. ${ }^{42}$ Estas consideraciones con respecto al ser como fuerza que va de dentro hacia fuera resultando ser algo completamente inherente, es lo que facilita la comprensión de la metáfora del lenguaje como espejo del mundo.

Así, pensar quiere decir hablar interiormente. Hablar significa pensar en voz alta. Si realmente pienso un objeto, ya estoy pensando en alguna de sus propiedades. Y si ponemos en conexión Ser, Fuerza y Lenguaje, como están

$41 \quad$ Ibid.p. 359.

42 Ibid. pp. 364-365. 
dimensionados en Leibniz y en Herder, aceptamos la recreación de nuestra alma por medio del pensamiento ya que a través del pensar es como el alma se va creando continuamente a sí misma (unidad) a partir de la pluralidad. ${ }^{43} \mathrm{La}$ idea del lenguaje como alma del pueblo (Volk) ya está en Herder.

En la nota número cuatro que hace el traductor, el profesor Pedro Ribas, nos rescata un texto que Herder habría tachado y que es importante para nuestro análisis:

De ahí que la utilidad de esta ciencia resida, las más de las veces, en las acepciones, convirtiéndose la metafísica, por consiguiente, una filosofía del lenguaje humano. ¿Qué campo más grande! ¡Cuánto queda en el aun por observar, ordenar, sembrar y cosechar! Después de la matemática, no hay otra filosofía que ilustre tanto el entendimiento que determine tanto los conceptos. Esta filosofía es la verdadera crítica de la razón pura y de la fantasía; sólo ella contiene en sí los criterios de los sentidos del entendimiento. ${ }^{44}$

Podemos preguntarnos: ¿por qué sería tan instructivo que comparásemos la designación, la sustantivización en las lenguas de diversos pueblos? Porque tal comparación nos mostraría la variedad de caracteres nacionales de sus diversos inventores, y al mismo tiempo la pluralidad de aspectos que podemos observar en las cosas. Y, por lo tanto, la circunstancia de la denominación misma. Estas propiedades reflejadas en la lengua no siempre serán las más esenciales dado que los motivos de su designación dependerán de las circunstancia de la existencia. A pesar de todo no se perdería el carácter esencial de la lengua en tanto expresión del entendimiento, ya que ninguna caracterización humana designa de forma esencial y completa. La Metacrítica entiende que el significado genuino de las palabras se constituiría, en todo caso, como una barrera contra su propio abuso. De tal modo que, «el lenguaje es y sigue siendo el libro-depósito del entendimiento humano». ${ }^{45}$ El lenguaje es el mapa del mundo y nosotros, seres pensantes y hablantes, somos parte de él. Por esta razón considera Herder que la mayor parte del lenguaje del entendimiento llega también a ser un índice del actuar y del padecer. Los verbos activos y pasivos son las ruedas motrices del habla humana. Es más, los principales sustantivos se forman a partir de ellos, por lo tanto, del actuar y del padecer, llegándose a la conclusión, advertida anteriormente en esa filosofía del lenguaje humano, de que en la configuración de las palabras de acción y pasión mediante género, modo, persona y tiempo se contiene

43 Cf. Herder: op. Cit. p. 365.

$44 C f$. Ribas: op.cit. 458. $\mathrm{N}$ del $\mathrm{T} \mathrm{N}$. .4 . En el escrito original se encontraba tachado Cf. Herder: Werke, 8, $M V$ p. 326.

45 Ibid. p. 404. 
un tesoro de denominaciones del entendimiento expresivo. A esta última razón se debe que en todas las lenguas los verbos son, precisamente, los que más han sufrido transformaciones a lo largo del tiempo. Han sido perfeccionados de la forma más variada ya que la lectura y el padecer constituyen toda la naturaleza, toda la vida, y, en consecuencia, la vida del hombre. Unidad-multiplicidad. Es importante recordar esta tensión para recalcar que el nacionalismo de Herder, para Isaiah Berlin, no pasa de ser un nacionalismo cultural que, señalando las características propias y singulares de una determinada lengua, como la lengua en la que hablan Kant y su crítico Herder, nos indica al mismo tiempo la pluralidad y singularidad y necesidad de otras lenguas.

En el nudo en el que estamos, el análisis de las palabras activas y pasivas, Herder afirma que a pesar de su cantidad tan grande se reducen a unas pocas clases principales. Unas indicarán un movimiento hacia nosotros o desde nosotros, bien de subida o de bajada, ya lenta o veloz, brusca o suave. Están designando su efecto sobre nosotros o qué parte de nosotros, con amor o sufrimiento, con simpatía o alejamiento. Lo decisivo es que «Hay una profunda intimidad en este aspecto del lenguaje, siendo expresada a su manera por cada lengua». ${ }^{46}$

Esta unidad-multiplicidad en el lenguaje se refleja cuando observamos el comportamiento lingüístico tan singular a la hora de designar el devenir de las cosas. Seguimos el ejemplo que nos da nuestro autor. El que algo exista posibilita una contemplación tranquila; pero el que algo nazca, el que una cosa surja de otra, constituye la gran maravilla diaria e instantánea de la naturaleza: «la expresión lingüística resulta aquí, claro está, recortada y rápida, [...] también en el campo de la expresión de la fuerza se muestra por doquier el mismo genio humano que no pudo avanzar sino reconociendo la causa en los efectos e imprimiendo sobre ella su distintivo, es decir un nombre».

De ahí que para Herder uno de los más grandes méritos de Leibniz haya consistido en haber introducido lo infinito en el campo de la metafísica, lo que significa que se habría podido introducir lo infinito en las facultades mismas del alma. De nuevo encontramos el hilo conductor entre pensamiento y lenguaje, ser y lenguaje, fuerza y lenguaje: el universo no es un todo acabado, sino que avanza hacia lo ilimitado. Estamos de acuerdo con Herder cuando afirma que «nunca le interesó al hombre un universo absoluto y terminado». Para Herder el acto del entendimiento, como para Leibniz, consiste en «el reconocimiento de la unidad dentro de la multiplicidad». ${ }^{47} \mathrm{Si}$ la ontología es la base de todo, lo es en la medida en que todos tienen necesidad de su lenguaje, aunque aquí se refiera nuestro autor a la filosofía del lenguaje universal del entendimiento.

47 Ibid, p. 406. 
Atendiendo a su naturaleza, la ontología ya no puede ser otra cosa «que la más pura Filosofía del lenguaje del entendimiento y la razón». ${ }^{48}$

Por lo tanto, la relación entre Ontología y Lenguaje es una consecuencia del análisis metacrítico de Herder del binomio unidad-multiplicidad. En el lenguaje humano también se adelanta lo universal a lo particular, a pesar de que aquel sólo fue conocido a través de éste. Cómo fue posible ver la unidad dentro de la multiplicidad no fue debido ni a la prisa ni a la evocación, sino al entendimiento mismo y a su forma de designar. Al designar, se incluía lo particular en lo universal, la parte en el todo. Sólo de esta manera se formó el lenguaje humano y esto no obedece únicamente a la necesidad que tenemos de crearnos, dentro del enorme e inmenso universo, un mundo que nos perteneciera en cuanto horizonte humano (son palabras del propio Herder), sino porque ese acto era la sustancia misma del entendimiento reconocedor. El universo se refleja en nuestro entendimiento y lo hace a través del lenguaje, un entendimiento reconocedor quiere decir que «no puede hacer otra cosa que encontrar dentro de lo universal lo particular y dentro de lo particular lo universal, para unir ambos».49

La Metacrítica se torna más tajante cuando entra en la temática de las palabras como alma, espíritu, persona, sustancia, materia, etc. Ahí nos señala Herder que todo lenguaje, sobre todo el lenguaje metafísico recibido de los escolásticos, se encuentra lleno de palabras repletas, a su vez, de conceptos indeterminados y toscos. El alumno las debe aprender de memoria por lo que se acostumbra a ellas empleándolas de forma automática. «En la mayoría de los casos, cada nuevo fundador de una secta ha inventado gran número de tales palabras oscuras. ¡Cuántas ha inventado, por ejemplo, la «filosofía crítica». Por eso si quisiéramos cuidar la razón verdadera frente a la dialéctica ilusión trascendental sería necesario limpiar el lenguaje con el que se presenta mediante «la aguja más cortante». ${ }^{50}$ Pero no echaremos más leña al fuego acusando el golpe recibido por la reseña crítica que había hecho Kant de Ideas. Tampoco nos detendremos en la resistencia que ofrecerá Herder en apoyo del criticado Leibniz por los seguidores de la filosofía crítica. Es más importante para nosotros entender que el lenguaje es el instrumento de la razón; pero no como una herramienta intercambiable por otra, sino del propio reconocimiento creador del entendimiento ante la increíble e inconmensurable e infinita variedad del universo. A nuestro entender, la genialidad de Herder consiste en haber relacionado el radio de acción de la fuerza de cada mónada (Leibniz) con la creatividad lingüística de cada pueblo (Volk). Si Kant alumbró el denominado «giro copernicano» correspondiente a que el universo solamente puede responder 
bajo el interrogante físico-matemático, por su parte, Herder ha adelantado el denominado «giro lingüístico».

¿Cómo? Logrando, al igual que las matemáticas, un nuevo calculo, los idiomas nacionales. Mientras se empleo en la filosofía una lengua greco latina que ni Aristóteles ni Cicerón hubiesen querido entender, se siguieron arrastrando las viejas baratijas de las abstracciones mal entendidas y forzando al espíritu dentro de esas formas verbales decrépitas. Pero, tan pronto como alguien se atrevió a pensar en $s u$ propia lengua, el entendimiento sano no se dejó dominar; desechó las envolturas de palabras extrañas reconociendo sus conceptos dentro de $s u$ lengua. ${ }^{51}$

Nos preguntamos: ¿no representa esto una crítica a la modernidad al considerar que el uso exclusivo y sistemático de la metodología filosófico-matemática es la «forma exterior» con la que la filosofía se habría relacionado hasta ese momento? He aquí, pues, las razones que proponemos para rescatar el pensamiento de Herder como pionero, en pleno Siglo de las Luces, de la hermenéutica.

Adriana Rodríguez Barraza. Doctora en Antropología Social por la Universidad Autónoma de Madrid. Ha sido becaria de la Agencia Española de Cooperación Internacional y miembro de distintos proyectos de investigación europeos y latinoamericanos. Profesora de la Universidad Anáhuac y de la Universidad Veracruzana (México).

\section{Línea de investigagación:}

$\mathrm{Su}$ investigación y docencia se centra en la Filosofía de la Cultura destacando en este sentido Los orígenes europeos del multiculturalismo 2008.

Dirección electrónica: arbarraza@hotmail.com

51 Ibid, p. 586. Las cursivas son de Herder. 